diet, who were under medical and dietary control at the Institute of Mother and Child in Warsaw (Poland). Anthropometric measurement, body composition (fat mass, lean mass, bone mineral content) and dietary constituents were assessed in all studied children. Body composition was measured by dualenergy X-ray absorptiometry. Dietary assessment was performed using a nutritional software program Dieta5. Concentrations of bone metabolism markers (osteocalcin - OC, Cterminal telopeptide of collagen type I - CTX) and myokines (myostatin and irisin) were determined in serum samples by immunoenzymatic assay. Statistical analyses were done using Statistica software. This study was approved by the Ethics Committee at the Institute of Mother and Child.

There were no significant differences in the anthropometric parameters: weight, height and body mass index in both studied groups. Compared with omnivores, vegetarians had similar bone mineral contents but lower $(\mathrm{p}<0.05)$ lean mass and percentage of fat mass. Average daily dietary energy intake was similar in both studied groups, however, vegetarians had a lower intake of protein and higher intake of carbohydrates compared with omnivores (both $\mathrm{p}<0.05$ ). The serum concentration of OC was significantly lower in children on a vegetarian diet compared with omnivores $(66.9 \pm 13.7$ vs. $85.2 \pm 20.5 \mathrm{ng} / \mathrm{mL}, \mathrm{p}<0.01)$. Additionally, levels of CTX were higher in vegetarians than in omnivores $(1.970 \pm 0.341$ vs. $1.597 \pm 0.351 \mathrm{ng} / \mathrm{mL}, \mathrm{p}<0.01)$. Serum myokines concentrations did not significantly differ in both studied groups of children, but we observed slightly higher (by about 15-20\%) levels of myostatin and irisin in vegetarians.

Our results show that a well-planned vegetarian diet with proper dairy and egg intake does not lead to changes in bone mass in prepubertal children.

However, children following a vegetarian diet had a higher rate of bone turnover and subtle changes in serum myokine levels.

\section{HEMATURIA AS AN EARLY SIGN OF MULTISYSTEM INFLAMMATORY SYNDROME IN CHILDREN (MIS-C): A CASE REPORT OF A BOY WITH MULTIPLE COMORBIDITIES}

Ana Generalić*, Maša Davidović, Ivanka Kos, Kristina Vrljičak, Lovro Lamot. University Hospital Centre Zagreb

\subsection{6/archdischild-2021-europaediatrics.63}

While clinical course of SARS-CoV-2 infection seems to be milder or asymptomatic within pediatric population, growing attention has been laid to the rare complication elicited by virus, multisystem inflammatory syndrome in children temporarily associated with COVID-19 (MIS-C). Published definition and criteria of MIS-C include persistent fever, multisystem involvement and elevated markers of inflammation, without obvious microbial inflammation or other plausible diagnosis. The aim of this case report is to emphasize diversity of symptoms of MIS-C.

We present a case of a ten-year-old boy with multiple comorbidities who developed MIS-C after asymptomatic SARS-CoV-2 infection. To our knowledge this is the first reported case of transient gross hematuria as an early sign of MIS-C. Beside hematuria, patient also presented persistent fever and elevated markers of inflammation, with no other sign of renal affection.
Moreover, he had discrete erythematous maculopapular rash on the right lower leg. Within the next two days, his condition continued to worsen despite the broad-spectrum antibiotic therapy. He started to vomit and developed abdominal pain, conjunctivitis, arrhythmia and mild left ventricular systolic dysfunction with hypotension and pleural effusion. High level of clinical suspicion for MIS-C was supported by laboratory findings (elevated ESR, CRP, proBNP, D-dimers and fibrinogen) along with positive $\operatorname{IgG}$

SARS-CoV-2 antibodies and negative microbiological cultures. The patient was given intravenous immunoglobulin (IVIG) at a dose of $2 \mathrm{~g} / \mathrm{kg}$ and began to show instantaneous clinical improvement, including downtrend of fever and inflammatory markers.

Despite the growing reports of the MIS-C in the literature, there is still paucity of studies describing the various clinical manifestation and laboratory finding in this serious condition which can be easily mistaken for many others inflammatory diseases. Therefore, pediatric professionals must be aware of (many) unusual presentations of COVID-19 associated disease in order to early recognize and treat such challenging patients.

\section{MULTISYSTEM INFLAMMATORY SYNDROME IN CHILDREN, MANAGEMENT IN A PERIPHERAL SETTING}

E Kelly*, M Jawad, M Azam, A Kalim. Wexford General Hospital

\subsection{6/archdischild-2021-europaediatrics.64}

Introduction In the context of the Covid 19 Pandemic Multisystem Inflammatory Syndrome in Children (MIS-C) is an important new differential requiring consideration, this report describes 2 cases seen in a secondary paediatric centre setting. Case Description Case 1: A 3 year-old boy presented with a four-day history of fever, malaise and decreased oral intake. The fever was persistent, it peaked at $40.8 \mathrm{C}$.

Over 4 days he had had 2 vomits but no other symptoms. He had no significant medical history and no known history of Covid 19 disease. Physical examination revealed no source of fever.

Case 2: A 14-month-old girl presented with a 1 day history of fever, malaise and decreased oral intake. She had no significant medical history and no known history of Covid 19 disease. No source of fever was evident on exam.

Initial investigations included chest $\mathrm{x}$-ray, urine culture, blood culture and throat/nasal swab for PCR for SARS CoV-2, all were negative.

Their markers of inflammation were elevated and continued to rise with persistent fever, despite treatment with IV ceftriaxone.

With no clear source of fever and no improvement, in consultation with the Infectious Diseases team in our tertiary referral hospital, we began treatment with intravenous immunoglobulin (IVIG), IV methylprednisolone and high dose aspirin for suspected MIS-C in Case 1, Case 2 was transferred to the tertiary centre for the same treatment at the ward level. With the IVIG infusion, all fever and symptoms resolved.

An Echocardiogram was organised for each in the acute setting and repeated at 6 weeks, they demonstrated normal cardiac systolic and diastolic function with no evidence of significant coronary dilatation. 
Case Discussion Though MIS-C is rare, with an incidence of $0.14 \%$ among children with SARS

CoV-2 infection according to one Systematic Review (Hoang Et al. 2020), it is an important new differential which must be borne in mind in cases of fever with no clear source. Both of these cases had a negative PCR test for SARS CoV-2 and no history of Covid 19 disease. No serological testing for SARS CoV-2 was available in our hospital setting. But in accordance with RCPCH guidelines this does not exclude the diagnosis of MIS-C

In previous studies as many as $71 \%$ of cases of MIS-C required PICU admission (Ahmed Et al., 2020), however not all are severely unwell and may be stable enough to be managed on a ward setting as described above.

\section{EXOGENIC AND ENDOGENIC FACTORS AFFECTING THE SUPPLY OF VITAMIN D IN HEALTHY CHILDREN AND ADOLESCENTS OF THE SOUTH OF RUSSIA IN WINTER- SPRING PERIODS}

Svetlana Dolbnya*, Viktoriya Kur'yaninova, Yuliya Melyanovskaya, Elena Kondratyeva, Leonid Klimov, Anna Dyatlova, Anastasiya Yagupova, Anna Tsutsaeva. Stavropol State Medical University, Stavropol 355017, Russian Federation

\subsection{6/archdischild-2021-europaediatrics.65}

Study objectives - to analyze the influence of exogenous and endogenous factors on the supply of vitamin D in children and adolescents living in southern Russia in the winter-spring period.

The study included 27 healthy children and adolescents, aged 3 months to 16 years, living in Stavropol $\left(45^{\circ} 02^{\prime} \mathrm{N}\right.$ $\left.41^{\circ} 58^{\prime} \mathrm{E}\right)$. Children under 3 years old were $9(33.3 \%), 4$ to 7 years old $-5(18.5 \%), 8$ to 11 years old $-6(22.3 \%), 12$ to 16 years old $-7(25.9 \%)$ people. Blood sampling was performed in February-March 2018. Vitamin D provision was assessed by the serum calcidiol level. Satisfactory supply was diagnosed at a level of $25(\mathrm{OH})$ D 30-100 $\mathrm{ng} / \mathrm{ml}$, insufficiency - 20 to $30 \mathrm{ng} / \mathrm{ml}$, deficiency - less than $20 \mathrm{ng} / \mathrm{ml}$.

The study of polymorphism of biotransformation genes was carried out by PCR and subsequent RFLP analysis. Polymorphisms selected for study included CYP2C9*2 (430C $>\mathrm{T}$; R144C), CYP2C9*3 (1075A $>$ C; I359L), CYP2D6*4 (1846G>A), CYP3A4*1B (-392C >T).

Median vitamin D availability was 34.6 [23.5-44.6] ng/ml. Vitamin D deficiency was detected in 5 (18.5\%) children, deficiency was also found in $5(18.5 \%)$ children, satisfactory provision was revealed in 17 (63.0\%) children.

There is a negative correlation between the age of children and the level of $25(\mathrm{OH}) \mathrm{D}: \mathrm{r}=-0.69, \mathrm{p}=0.0001$, as well as between body weight and calcidiol level $\mathrm{r}=-0.64, \mathrm{p}=$ 0.0004

Direct correlation was found between the dose of cholecalciferol products and serum $25(\mathrm{OH}) \mathrm{D}$ level, $\mathrm{r}=-0.60, \mathrm{p}=$ 0.001 .

With CC polymorphism (CYP2C9*2) 25(OH) D $<30 \mathrm{ng} /$ $\mathrm{ml}$ was detected in $8(80.0 \%)$ children, and more than $30 \mathrm{ng} /$ $\mathrm{ml}$ - in 2 (20.0\%), with CT - in 2 (20.0\%) and in 2 $(11.8 \%)$ respectively. With polymorphism AA (CYP2C9*3) 25 $(\mathrm{OH}) \mathrm{D}<30 \mathrm{ng} / \mathrm{ml}$ was in $9(90.0 \%)$ children, more than $30 \mathrm{ng} / \mathrm{ml} \mathrm{-} \mathrm{in} 15$ (88.2\%), with CA - in 1 (10.0\%) child and in $2(11.8 \%)$ children respectively. With TT polymorphism (CYP3A4*1B) $25(\mathrm{OH}) \mathrm{D}<30 \mathrm{ng} / \mathrm{ml}$ was detected in 9
(90.0\%) children, and more than $30 \mathrm{ng} / \mathrm{ml} \mathrm{-} \mathrm{in} 16$ (94.1\%) children, with TC - in $1(10.0 \%)$ and in 1 (5.9\%) respectively. With polymorphism GG (CYP2D6*4) 25(OH)D $<30$ $\mathrm{ng} / \mathrm{ml}$ was detected in $7(70.0 \%)$ children, and more than 30 $\mathrm{ng} / \mathrm{ml}$ - in $13(76.5 \%)$ children, with GA $25(\mathrm{OH}) \mathrm{D}<30 \mathrm{ng} /$ $\mathrm{ml}$ was in $2(20.0 \%)$, more than $30 \mathrm{ng} / \mathrm{ml}$ - in $4(23.5 \%)$, AA was only in $1(10.0 \%)$ child with vitamin D less than 30 $\mathrm{ng} / \mathrm{ml}$.

Insufficient vitamin D levels were found in 37.0\% of healthy children and adolescents living in the Southern Russia. The serum calcidiol level depends on age; the older is the child, the higher is the likelihood of hypovitaminosis D. Intake of cholecalciferol product is an effective way to prevent vitamin D deficiency and insufficiency, while hypovitaminosis $\mathrm{D}$ was not convincingly associated with any of the studied polymorphisms of biotransformation genes: CYP2C9*2, CYP2C9*3, CYP2D6*4, CYP3A4*1B.

\section{\begin{tabular}{l|l}
\hline 66 & IRON DEFICIENCY ANEMIA IN ADOLESCENT - AN
\end{tabular} UNEXPECTED DIAGNOSIS: CASE REPORT}

Alexandra M Rodrigues*, Rita Andrade, Joana Filipe Ribeiro, Catarina Francisco, Leonor Salicio, António Manso, Sónia Santos. Hospital de Sousa Martins - Unidade Local Saúde da Guarda, Guarda, Portugal

\subsection{6/archdischild-2021-europaediatrics.66}

Background Iron deficiency anemia (IDA) in adolescents is very common. The major causes at this age are an inadequate diet. Obesity or malnutrition are also causes of IDA. Besides that, many adolescents have genital losses (girls) or gastrointestinal tract disorders like inflammatory bowel disease, coeliac disease, hemorrhoids or diverticulitis. Moreover, less common chronic or acute diseases can cause this anemia.

Case Report A 17 year old female was oriented from primary care to pediatric evaluation because of iron deficiency anemia with failure of oral iron treatment after six months. In pediatric evaluation, the adolescent presented inadequate diet and no other problems. There were doubts about compliance with the iron treatment previously prescribed. She was previously healthy, had no symptoms or history of hereditary diseases or other family relevant pathology and had regular menstruation. As such, in the first evaluation, an extensive analytical study was requested, a more assertive oral iron treatment was initiated and diet correction was explained. One month later, the adolescent maintained IDA. As such, the iron treatment was doubled. Besides that, a slight increase in fecal calprotectin and thrombocytosis was detected. The rest of the analytical study did not have any changes. Thus, gastroenterology evaluation was requested for suspicion of inflammatory bowel disease. After three months, the adolescent returned and referred feeling right hypochondrial pain over the last two months which was controlled with paracetamol. Ultrasound evaluation of the abdomen was performed and revealed circumferential thickening of the ascendant colon and many mesenteric adenophaties. A CT scan was done which showed an eight centimeter long tumoral mass in the ascendant colon, as well as an inferior vena cava involvement and bulky adenopathies in venous drainage.

The adolescent was transferred to a central hospital and evaluated by pediatric oncology and surgery. A percutaneous biopsy revealed mucinous adenocarcinoma with colorectal phenotype. This diagnosis led to a surgery in which laparoscopic right hemicolectomy, epiplon excision and peritonectomy were 